\title{
Are investors guided by the news disclosed by companies or by journalists?
}

Article

Accepted Version

Shang, Z., Brooks, C. and McCloy, R. (2014) Are investors guided by the news disclosed by companies or by journalists? Journal of behavioral and experimental finance, 1. pp. 45-60. ISSN 2214-6350 doi: https://doi.org/10.1016/j.jbef.2014.01.003 Available at https://centaur.reading.ac.uk/36268/

It is advisable to refer to the publisher's version if you intend to cite from the work. See Guidance on citing.

Published version at: http://www.sciencedirect.com/science/article/pii/S2214635014000069

To link to this article DOI: http://dx.doi.org/10.1016/j.jbef.2014.01.003

Publisher: Elsevier

All outputs in CentAUR are protected by Intellectual Property Rights law, including copyright law. Copyright and IPR is retained by the creators or other copyright holders. Terms and conditions for use of this material are defined in the End User Agreement.

\section{www.reading.ac.uk/centaur}

\section{CentAUR}

Central Archive at the University of Reading

Reading's research outputs online 
NOTICE: this is the author's version of a work that was accepted for publication in the International Review of Financial Analysis. Changes resulting from the publishing process, such as peer review, editing, corrections, structural formatting, and other quality control mechanisms may not be reflected in this document. Changes may have been made to this work since it was submitted for publication. A definitive version was subsequently published in the Journal of Behavioral and Experimental Finance, 1, 45-60, (2014), DOI: http://dx.doi.org/10.1016/j.jbef.2014.01.003 


\title{
Are Investors Guided by the News Disclosed by Companies or by Journalists? \\ Zilu Shang \\ ICMA Centre, University of Reading
}

\author{
Chris Brooks* \\ ICMA Centre, University of Reading
}

Rachel McCloy

School of Psychology and Clinical Language Sciences

\begin{abstract}
Most previous studies demonstrating the influential role of the textual information released by the media on stock market performance have concentrated on earnings-related disclosures. By contrast, this paper focuses on disposal announcements, so that the impacts of listed companies' announcements and journalists' stories can be compared concerning the same events. Consistent with previous findings, negative words, rather than those expressing other types of sentiment, statistically significantly affect adjusted returns and detrended trading volumes. However, extending previous studies, the results of this paper indicate that shareholders' decisions are mainly guided by the negative sentiment in listed companies' announcements rather than that in journalists' stories. Furthermore, this effect is restricted to the announcement day. The average market reaction -measured by adjusted returns-is inversely related only when the announcements are ignored by the media, but the dispersion of market reaction -measured by detrended trading volume - is positively affected only when announcements are followed up by journalists.
\end{abstract}

JEL classifications: G10, G14

Key words: information sentiment, regulatory announcement, mass media stories, media coverage, disposal

* Address for correspondence: Chris Brooks, ICMA Centre, Henley Business School, University of Reading, Whiteknights, Reading RG6 6BA, UK; tel: (+44) (0) 118931 6768; fax: (+44) (0) 1189314741.

Acknowledgement: We would like to thank an anonymous referee for useful comments on a previous version of this paper. 


\section{Introduction}

Information sources are crucial in financial markets. The two main branches of studies on how information affects stock market performance have focused on quantitative (numerical) information and qualitative (textual) information. Financial scholars have traditionally preferred to analyse numerical information, being critical of the wide variation in interpretation of textual expression in different contexts (Brun and Teigen, 1988).In addition, shareholders might hold the opinion that the numerical data in listed firms' reports are more precise and credible (Botosan, 1997; Mercer, 2004). However, this does not mean that textual information is not important concerning stock market performance. In fact, textual expression is at least as important as numerical information in driving stock market performance. Investors are more likely to be attracted by textual expressions that explain risk and are able to understand them better (Visscherrs et al., 2009). From the perspective of the information outlets of listed companies, managers may create a favourable narrative if possible (Clatworthy and Jones, 2006; Schleicher, and Walker, 2010; Guillamon-Saorin et al., 2012), carefully selecting among numerical, textual, and graphic information (Skinner, 1994; Kasznik and Lev, 1995; Muiño and Trombeta, 2009).

Most previous studies on how the qualitative cues of information outlets affect market performance have focused on two areas: information coverage and information tone. ${ }^{1}$ Studies on information coverage show that both media and analyst coverage significantly affect stock market performance, depending on the specific type of press release (Bamber and Cheon, 1995; Klibanoff et al., 1998; Lee and Swaminathan, 2000; Diether et al., 2002; Bushee and Miller, 2007; Fang and Perress, 2009; Engelberg and Parsons, 2011; Gurun and Butler, 2012; Solomon, 2012). This paper relates to the second branch and addresses the relationship between the tone of disposal stories and stock market performance - returns and trading volumes.

In this paper, the tone or the sentiment of disposal stories is measured by the occurrence of positive, negative, and uncertainty language in accordance with the Loughran and McDonald Financial Sentiment Dictionaries (LMFSD). Most previous studies on how

\footnotetext{
${ }^{1}$ There are some other studies finding that vocal cues of managers during conference calls (Mayhew and Wenkatachalam, 2012), the number of questions that managers refuse to answer in conference calls (Hollander et al., 2009), and discussions on the Internet (Antweiler and Frank, 2004; Clarkson et al. 2006), also significantly affect stock market performance.
} 
the sentiment of information affects market performance have analysed earnings-related information outlets, sampling either the regulatory announcements (Abrahamson and Amir, 1996; Loughran and McDonald, 2011) or the voluntary disclosures (Henry, 2008) released by listed companies themselves.

Others emphasise the importance of how the mass media report earnings-related information about listed companies to readers (Tetlock, 2007; Tetlock et al., 2008; Gurun and Butler, 2012). Theoretically, as long as a piece of information may affect the fundamentals of the underlying company, the sentiment released by the information itself might also affect market performance in the same way as the earnings-related information. Weak evidence is found from research on news about corporate governance changes in the Italian media (Carretta et al., 2011). However, this cannot be generalised to other types of information outlets in other stock markets. Therefore, the first intention of this paper is to find out whether, as well as earnings and governance related information, the sentiment of information revealed by other types of fundamental disclosures can explain stock performance in a mature equity market. This study emphasises disposal transactions, which theoretically relate to companies' fundamental values because of their impacts on a company's liquidity position, future productivity and profitability, and on-going strategies. In this paper, we define a disposal as including any divesture of a subsidiary from the parent company, the disposal of tangible or intangible assets, or the divesture of share holdings in other companies - any situation where the Regulatory News System classifies the information as a 'disposal'. The results convey that the sentiment in disposal press releases does affect stock performance, from the perspectives of both returns and trading volumes. Consistent with previous studies, negative words have a more significant impact than other types of sentiment (Tetlock, 2007; Tetlock et al., 2008; Loughran and McDonald, 2011; Gurun and Butler, 2012).

Shareholders have two main information sources - the original announcements made by listed companies and the stories reproduced by journalists or analysts. ${ }^{2}$ However, no one can guarantee that listed companies and journalists (analysts) will tell the same story in an identical way, as they serve different purposes (Fang and Peress, 2009). In addition, sometimes the mass media may revive a stale news item but the market responds to it as the latest one (Huberman and Regev, 2001; Cavalho et al., 2011; Tetlock, 2011). Investors,

\footnotetext{
${ }^{2}$ Investors may also receive information from an asset manager or analyst. This, perhaps, represents a third source of information that we do not directly address in this paper.
} 
especially individuals, who are not able to continually monitor share prices and cannot trace every single announcement made by their investee companies, may derive more information from journalists and/or analysts. Furthermore, shareholders may treat journalists' and managers' stories differently if they realise, for example, that the mass media are prone to use fewer negative words when reporting news about local firms (Gurun and Butler, 2012) or that managers tend to select the information they provide and how they interpret it (Skinner, 1994; Kaznik and Lev, 1995). As Kohari, Li, and Short(2009) have documented, the sentiment inconsistency between listed companies and analysts, another motivation of this paper is therefore to examine the possible change in sentiment between listed companies and media journalists and to address the question of whether investors follow listed companies or journalists more closely. In endeavouring to explain the sentiment in information concerning earnings-related press releases, previous studies cannot isolate the impacts related to companies' announcements from those of media stories. ${ }^{3}$ Unlike earnings-related stories, which exhibit mass media clusters around announcement dates (Tetlock et al., 2008), disposal announcements are dispersed across the calendar year so that the comparison of market reactions to listed companies' announcements and media stories is possible. This study therefore analyses two subsamples and demonstrates that market participants treat the sentiment in listed companies' stories differently from how they value mass media stories. Generally, the effect of negative sentiment in companies' announcements on non-firm specific information adjusted returns is significant when the original announcements are not reproduced by the media; while its effect on detrended trading volumes is significant only when the original announcements are followed by journalists.

The layout of this paper is as follows. Section 2 gives a brief review of previous studies on the impacts of information sentiment on stock market performance. Section 3 presents the information data which are analysed in this paper and how information sentiment and market performance are measured. Section 4 presents the study's results, including descriptive statistics of the data, the results related to returns, and those related to trading volumes. Section 5 presents some general conclusions.

\footnotetext{
${ }^{3}$ It is difficult to establish a sample of earnings announcements without corresponding media news because both reporters and analysts are attracted by earnings announcements, so that media news tends to cluster around such announcements (Tetlock et al., 2008).
} 


\section{Information Sentiment and Stock Market Performance}

Although "whispers" do play some role in the stock market (Bagnoli et al., 1999; Antweiler and Frank, 2004; Clarkson et al., 2006), information is mainly gained from two resourcesthe press releases of listed companies and the stories generated by the mass media. Therefore, previous studies have naturally divided into two streams - how the stock market reacts to the sentiment embedded in announcements made by listed companies (Abrahamson and Amir, 1996; Henry, 2008;Kothari et al., 2009; Loughran and McDonald, 2011) and to the tone of mass media stories (Tetlock, 2007; Tetlock et al., 2008).In these studies, when negative and positive words are analysed separately, stock market performance appears to be more sensitive to negative words than to positive ones, especially when sentiment is measured in accordance with the Harvard-IVPychosociological Dictionary (Abrahamson and Amir, 1996; Tetlock, 2007; Tetlock et al., 2008; Loughran and McDonald, 2011). One possible explanation is that the communication teams of firms commonly frame negative information in positive words (such as "not profitable") but rarely vice versa (Loughran and McDonald, 2011). Nevertheless, Loughran and McDonald (2011) report that $73.8 \%$ of the negative words in the Harvard-IV-4 Dictionary $^{4}$ do not typically present a negative tone in the financial sphere. LMFSD has therefore been developed specifically for textual analysis in the financial sphere and it is used, in this paper, to quantify the sentiment in the sampled disposal announcements and media stories.

In a wide-ranging study of corporate $10-\mathrm{K}^{5}$ reports in the US, Loughran and McDonald (2011) document that negative, uncertainty, strong modal, and weak modal words negatively drive the excess return in the event period; but negative words positively affect excess trading volumes during the event period. Another study, which analyses the president's letters, conveys that negative words are predictors of both current and future accounting-based performance (Abrahamson and Amir, 1996). In addition to regulatory disclosures, the sentiment of the voluntary earnings-related outlets are also found to significantly influence returns and accounting-based performance (Henry, 2008).Besides the potential effects caused by negative words, those that relate to positive and uncertainty

\footnotetext{
${ }^{4}$ This is a shorthand for the Harvard-IV-Pychosociological Dictionary.

${ }^{5}$ According to the US Securities and Exchange Commission (SEC), listed companies must submit annual reports on Form 10-K which "provides a comprehensive overview of the company's business and financial condition and includes audited financial statements".
} 
words are also therefore analysed in this paper. Although the results confirm a more significant influence of negative words, positive and uncertainty words do also exhibit some predictability about future returns under certain circumstances.

Research on the mass media has shown the impact of media coverage on investors' reactions. For example, the pessimism of the Wall Street Journal (WSJ) can explain the downward pressure on market prices, and negative words have a stronger correlation with price performance than other categories of sentiment words (Tetlock, 2007). Tetlock et al. (2008) integrates stories from the WSJ and Dow Jones News Service (DJNS), focusing on the impact related to negative words and finds that they could predict future corporate earnings and returns. They also find that the timeliness of mass media stories might be a critical variable in determining the effectiveness of the impact of negative words on stock price performance. ${ }^{6}$ However, the most immediate information resource in stock markets, especially in mature markets like the US and the UK, should be the announcements made by listed companies themselves. Both analysts' reports and journalists' stories are fundamentally informed by these announcements. From another perspective, although there is evidence to show that analysts' reports are less optimistic (pessimistic) than the original positive (negative) information disclosed by firms (Kothari et al., 2009), there is little evidence to convey whether mass media stories deliver the same sentiment as those disclosed by listed companies. Both disposal announcements and corresponding media news are thus collected, so that their impacts can be analysed separately. The results suggest that mass media stories tend to use more negative words and fewer positive words than the original disposal announcements. Mass media stories are also different from company announcements in that they use a more diverse range of negative words.

The majority of studies on the relationship between information sentiment and market performance use earnings-related information. Although such information does evoke great attention from stock market participants, other categories of information, as long as they reflect potential changes in the fundamental values of a company, should also significantly

\footnotetext{
${ }^{6}$ In Tetlock et al. (2008), they sample both stories from the WSJ and DJNS. They find that the negative words used in the DJNS negatively correlate with excess returns on the day following the stories but the coefficient on the negative words in the WSJ variable is not statistically significant. Naturally, DJNS releases intraday news, which is more timely than WSJ stories, which are based on the information of the previous day. Therefore, excess returns are more closely correlated with the tone of DJNS stories than with that of WSJ stories.
} 
affect market performance - for example, mergers and acquisitions (M\&A), additional listings (Zhang, 2006), inclusion in the FTSE 100 (Tetlock et al., 2008), and so on. Disposal disclosures should theoretically have a significant effect on a company's fundamental value and previous studies have shown that disposal decisions have a close relationship with the underlying company's management, accounting performance, and market performance (Strong and Meyer, 1987; Collins and Henning, 2004). Compared with other types of regulatory disclosures, it is also easier to pin down when a disposal announcement is officially made and the announcements do not cluster across the calendar year (this will be discussed in detail in Section III). This paper extends research on information sentiment from earnings disclosures to disposals and extends research on asset write-downs from numerical to qualitative information.

\section{Data and Methodology}

\subsection{Data and Sample Selection}

Listed companies' announcements can be generally classified as regulatory and voluntary disclosures. This paper analyses regulatory announcements which have to be published in a timely manner with adequate information. Regulatory announcements are collected from the Regulatory News System (RNS) supported by the London Stock Exchange (LSE). RNS announcements are grouped into ten major areas ${ }^{7}$ and are further divided into 108 subheadlines. One of these sub-headlines, disposal announcements, exhibits some special characteristics which enable them to be the target announcements for this paper. Besides being part of a firm's normal operating strategy and regularly attracting investors' attention, it is easier to identify the precise date when disposal decisions are officially announced. A listed company commonly declares a disposal decision via a single announcement rather than a sequence of them. A typical example of a sequence of announcements concerning a single decision made by a listed company relates to M\&A. ${ }^{8}$ Disposal announcements are

\footnotetext{
${ }^{7}$ The announcement headlines provided by RNS are classified as company appointments, directors, and meetings; deals, transactions, and operational updates; offers; financial statements, dividends, and corporate actions; other statements and announcements; shareholder and POTAM disclosures; equity, debt, and investment trusts; market, RNS, and related announcements, documents and circulars; and prospectus directive filings.

${ }^{8}$ The initial notification of an acquisition is usually accompanied by a sequence of disclosures about any significant movement of the deal and the "decision whether a takeover/merger has been referred to the Competition Commission for investigation or the Secretary of State for Trade and Industry".
} 
spread across the whole calendar year rather than occurring at particular fixed dates. These are more likely to be published without heavy media coverage around an announcement day than, for example, financial and management statement announcements (Tetlock et al., 2008).It is also less common to observe other types of announcements that might significantly drive stock performance close to the day when a disposal announcement is published. From another perspective, a disposal decision is seldom straightforwardly linked to other operating activities by the company in the announcement itself. ${ }^{9}$ In general, a disposal announcement is analysed mainly because the announcement day can be clearly identified and the effects related to the announcement can be analysed without the disturbance of other announcements or media news. As the LSE only provides regulatory announcements for the previous two years, all disposal announcements made by FTSE 100 companies from March 2010 to December 2012 are collected from RNS. ${ }^{10}$ During this period, 196 disposal announcements were published.

In this paper, the analysis not only concentrates on the effects caused by the disposal announcements themselves but also on the related influences caused by these announcements and their corresponding mass media stories. The whole sample is divided into two sub-samples which are labelled below as RNS Only and Corresponding RNS (Cor. RNS). The disposal announcements which are not accompanied by mass media stories (RNS Only) are compared with those which have corresponding stories (Cor. RNS) to address the question of whether the sentiment presented by a mass media story deviates from that delivered by the initial announcement and whether it affects stock performance differently. When the corresponding stories are collected from PreQuest, FTSE 100 companies are found have much broader media coverage than other companies which are below the FTSE 100. The consequence is that when switching the sample index to, for example, the FTSE 350, the total number of disposal announcements via RNS is doubled while the total number of corresponding stories only slightly increases. In this situation, when the effects on the RNS-Only sample are compared with those of the Cor. RNS

\footnotetext{
${ }^{9}$ For example, announcements concerning additional listing, the issue of debt and the issue of equity usually include information about how the new funds will be used, the performance of the company, the financial position of the company, and so on.

${ }^{10}$ The first slot of data collection was undertaken in March 2011 and the second slot at the end of 2012. Therefore, a thirty-four-month sample is analysed in this paper, although the LSE only provides data for the previous twenty-four months. This sample of daily data is also used in the estimation of betas in the market model as discussed later in the paper.
} 
sample, the results should mainly reflect the differences caused by the sizes of the companies. The FTSE 100 is therefore chosen as the sample index rather than other, broader indices.

For each disposal announcement, its corresponding mass media story is found from PreQuest. In total, 116 of the 196 RNS announcements have at least one corresponding mass media story. When Company A announces its decision to dispose one of its subsidiaries or assets (Section B), to be identifiable as a corresponding story, a piece of mass media news should fulfil all of the following criteria: the story must focus on precisely this disposal decision which was made by Company A; the name of the disposing Company A, the disposed Section B, and the company which is willing to take over Section $\mathrm{B}$, have to be mentioned; and Company A has to be mentioned in the title of the story. If, for one RNS announcement, there is more than one corresponding story that fulfils these requirements, the earliest published one is included in the sample. These corresponding stories are published via sixteen media outlets and the top five (in order) are the Financial Times, Daily Telegraph, Evening Standard, The Times, The Herald, and Daily Mail, which in total account for $78.45 \%$ of the sampled corresponding stories. ${ }^{11}$

Two screens are implemented to pool an announcement and its corresponding story, if there is one, into a combined sample. A disposal statement has to be announced before 15:30 on a normal trading day so that investors have an hour to fully react to the newly released information (Ederington and Lee, 1993; Berry and Howe, 1994; Tetlock et al., 2008). In addition, there should be no other regulatory announcements which might significantly affect the stock performance ${ }^{12}$ released during a five-day time window (two days before and after the disposal announcement day).In total, 141 qualified disposal announcements have been retrieved in this paper and 84 of them have corresponding stories. At least one disposal announcement is included for 57 companies in the FTSE 100.This sample will be referred as the "Whole Sample" below and will be used to analyse

\footnotetext{
${ }^{11}$ The sixteen media outlets are Financial Times, Daily Telegraph, Evening Standard, The Times, The Herald, Daily Mail, Daily Post, The Independent, City A.M., BreakingNews, The Yorkshire Post, Irish Independent, Irish Time, Liverpool Echo, South Wales Echo, and Belfast Telegraph.

${ }^{12}$ Regulatory announcements concerning the launch of new product lines, additional listings, dividend declarations, financial statements, disposals, $M \& A$, and new joint ventures, are found to be able to significantly affect stock performance when screening the initial RNS disposal announcements. Other types of announcements - for example, issues of debt, which might also drive stock performance - are not found around the five-day time window of any disposal announcements in the initial sample.
} 
whether the quantity of sentiment words presented in the announcements influence stock performance on the announcement day and whether they have predictability.

\subsection{Measures of Unique Sentiment Words}

The tone of words is measured in accordance with LMFSD, which is composed of six subdictionaries - negative words (e.g., close, dispose, loss, etc.), positive words (e.g., improvement, leading, opportunity, etc.), uncertainty words (e.g., believe, confuse, possible, etc.), litigious words (e.g., adjudge, crime, justice, etc.), strong modal words (e.g., always, must, never, etc.), and weak modal words (e.g., almost, may, possible, etc.).The analysis of this paper concentrates on three types of sentiment - positive, negative, and uncertain.

Most previous studies measure the tone of a piece of text by the raw count of sentiment words based on a simplifying assumption that the repeated occurrence of a sentiment word does not strengthen or weaken its effect on market performance (Tetlock et al., 2008). However, Loughran and McDonald (2011) argue that repeated occurrence should be considered in content analysis studies because commonality decreases the salience of a sentiment word. Therefore, they suggest that, instead of using the raw word counts in content analysis, term weighting ${ }^{13}$ word counts are more rigorous. Although their results concerning $10-\mathrm{K}$ files suggest that this approach improves the explanatory effect of sentiment words on trading volumes, the improvements in explaining excess returns are barely significant. One possible reason is that the repeated occurrence of a sentiment word in a document might eventually increase its salience (Iselin, 1988) and, hence, the marginal informativeness of this word might increase within the document. The term weighting approach considers the potential effect of a more common word, which tends to create less impact than a rarely used word in a corpus but it fails to measure the fact that a word might attract more attention from the audience by occurring more times in an individual document. Considering the difficulties of involving both phenomena in measurement, the

\footnotetext{
${ }^{13}$ The term weighting word counting approach (Loughran and McDonald, 2011) measures the impact of a sentiment word based on its commonality. It integrates three components: the occurrence of a sentiment word within a document, the length of the document, and the commonality of the sentiment word within in the entire corpus. As a consequence, the marginal informativeness of a sentiment word in a specific document decreases along with the increase of its observed frequency in the entire corpus.
} 
quantity of sentiment information in a disposal announcement or its corresponding story is simply measured by the number of unique sentiment words that appear in the main text. ${ }^{14}$

The number of sentiment words that appear in an announcement or a story is counted following a three-step procedure. The first step is replacing some phrases by abbreviations so that they are counted as a single word. These replaced phrases include company names, people's names and occupations when their opinions were cited, names of institutions, dates, and geographic areas. For example, Scottish and Southern Energy is replaced by SSE, Chief Executive is replaced by CEO, the US Securities and Exchange Commission is replaced by SEC, the United States is replaced by US, and so on. The purpose of phrase replacement is to prevent the influence of different textual styles, which might be adopted by different companies or newspapers, on the total number of words in an article, as some of them prefer to use abbreviations while others prefer the full phrases. By this replacement procedure, the total number of words in an article should not be biased by such preferences. The total number of words in an article after word-replacement is used in the following statistical procedures. This also prevents words that simply present some objective subject being counted as sentiment words.

In the second step, the original LMFSD sub-dictionaries are reconstructed so that they can be used to count how many unique sentiment words appear in an article. When several words which are formed from the same root appear in an article, they might repeatedly deliver the same sentiment to the audience. Instead of pooling the total number of times that, for example, positive words appear in an article and analysing how this would affect stock performance, it is the number of unique positive words which have different roots that is used as an independent variable. Accordingly, the positive word lists of LMFSD are reorganised by combining the words which present the same root in different grammatical tenses as one single grouped-word. For instance, 'assure', 'assured', 'assures', and 'assuring' are pooled into a group-word 'assure'. In this case, if both 'assured' and 'assures' appear in an article, they are counted as one unique positive word in this study

\footnotetext{
${ }^{14}$ In the disposal announcements of some firms, there is a "note to director" section following the main text of the announcement. Commonly, firms briefly introduce the company making the disposal announcement, the assets or the company that are being disposed, and the company which is to buy the disposed section. This section in RNS announcements is not included in the analysis because it purely reflects the company's own preference, not every company's announcements are accompanied by a "notes to director" section, and the length of this section can range from tens to hundreds of words.
} 
instead of two. The same procedures are adopted for the negative and uncertainty word lists.

The last step is to count the total number of unique sentiment words used in an article. Punctuation marks are deleted so that an article becomes a group of words - a "word bag". Every disposal announcement and corresponding story is transferred to an independent word bag. Then the word bags are matched with the positive, negative, and uncertainty subdictionaries individually to count how many words in each word bag are defined as having a sentiment value. Simultaneously, via this procedure, all sentiment words that appear in each disposal announcement or corresponding story are highlighted so that the fact that a small number of sentiment words is much more frequently observed than others can be analysed.

\subsection{Information Sentiment and Share Performance}

Two measures of sentiment words are defined: raw fractions of sentiment words (POS, NEG, and UNC) and detrended fractions of sentiment words (pos, neg, and unc). Taking positive words as an example, POS (equation (1)) is the fraction of the number of unique positive words in an announcement or a media story. All announcements or media stories in a calendar year are combined into a single composite story. Then the raw fractions of positive words (POS) in each composite story (2010, 2011, and 2012) are adjusted by the average POS in that calendar year (equation (2)) and the detrended fraction of positive words (pos) is used to evaluate how positive words contribute to price and trading volume changes on the announcement day and whether they have the capability to predict stock performance on the day after the announcement. The detrended fractions of negative (equation (3) and (4)) and uncertainty (equation (5) and (6)) words are calculated by the same approach and unit-root tests indicate that pos, neg, and unc are stationary.

$$
\begin{gathered}
P O S=\frac{\text { Number of Unique Positive Words }}{\text { Total Number of Words }} \\
\text { pos }=\frac{\text { POS }}{\text { Average POS in a Calendar Year }} \\
N E G=\frac{\text { Number of Unique Negative Words }}{\text { Total Number of Words }} \\
n e g=\frac{N E G}{\text { Average NEG in a Calendar Year }} \\
U N C=\frac{\text { Number of Unique Uncertainty Words }}{\text { Total Number of Words }}
\end{gathered}
$$




$$
u n c=\frac{U N C}{\text { Average UNC in a Calendar Year }}
$$

For a particular example of a firm announcement, stock market participants might expect a certain level of sentiment in the texts of the announcement itself according to their previous experience. The market participants' expected quantity of sentiment in a disposal announcement is measured by the average fraction of a type of sentiment word during a calendar year (Tetlock et al., 2008). Using the calendar year average rather than a sample period average eliminates any potential change in textual style during the sample period. For instance, the average fraction of uncertainty words decreased from $0.9 \%$ in 2010 to $0.64 \%$ in 2011 , and further decreased to $0.51 \%$ in 2012 . The detrended fraction of sentiment words also shows whether the quantity of sentiment that is delivered via an article is above or below the expectations of market participants who might use their expectations as an anchor. In an efficient market, the unexpected quantity of sentiment revealed by an announcement might have more significant effects on share performance than the expected part. Therefore, the primary measures of announcements and corresponding story sentiments are the detrended fractions of the three types of sentiment words. Share performance is measured by adjusted returns and detrended trading volumes. Adjusted returns reflect the shareholders' average reaction towards a piece of information. Trading volumes, by contrast, reflect the indigenous differences among shareholders' reactions (Beaver, 1968; Kim and Verrecchia, 1999).

Benchmark returns $\left(E\left(R_{i t}\right)\right)$ are estimated by the single index model (equation (7)). As this paper concentrates on the effects related to disposal announcements, which are firmspecific, in an isolated five-day time window, the beta for each single stock $\left(\hat{\beta}_{i}\right)$ is estimated using the corresponding FTSE 100 stock index. Therefore, after being adjusted by the benchmark return (equation (8)), the adjusted return $\left(A R_{i t}\right)$ should be that mainly contributed by firm-specific information. In the context of this paper, adjusted returns should be mainly led by disposal announcements because other influential announcements are screened from a five-day time window.

$$
\begin{aligned}
& E\left(R_{i t}\right)=\hat{\beta}_{i} R_{M t} \\
& A R_{i t}=R_{i t}-E\left(R_{i t}\right)
\end{aligned}
$$

The effects of sentiment words on adjusted returns (the average shareholders' reaction) is analysed at two time points - on the announcement day and on the day after the 
announcement. In both situations, two control variables are included: log market capitalisation $(\log M C)$ and $\log$ market to book ratio $(\log P B)$ to control for the potential influences of the sizes of listed companies and whether they are value or growth companies. As negative and positive words might be observed in a single story at the same time, two dummy variables separate the sentiment of a disposal announcement into two conditions there are more unique positive words (optimistic) and there are more unique negative words (pessimistic).The first dummy factor $\left(D_{1}\right)$ measures the degree of optimism of announcements, which is one when the raw fraction of negative words in a disposal announcement is smaller than that of positive words (RNS NEG $<$ RNS POS) and is zero otherwise. The second dummy factor $\left(D_{2}\right)$ measures the degree of pessimism of announcements, which is one when the raw fraction of negative words in a disposal announcement is larger than that of positive words (RNS NEG > RNS POS) and is zero otherwise.

The announcement day effects are analysed by a regression (equation (9)) where the announcement day adjusted return $\left(A R_{0}\right)$ is the dependent variable and includes eight independent variables (three control variables, two dummy factors, and three main test variables). Besides $\log M C$ and $\log P B$, the third control variable is the one-day lagged adjusted return $\left(A R_{-1}\right)$. The three main variables tested are the detrended fractions of positive words (pos), negative words (neg), and uncertainty words (unc). ${ }^{15}$

$A R_{0}=\alpha_{0}+\beta_{\text {pos }, 0}$ pos $+\beta_{\text {neg }, 0}$ neg $+\beta_{\text {unc }, 0}$ unc $+\beta_{\log M C, 0} \log M C+\beta_{\log P B, 0} \log P B+$ $\beta_{A R-1,0} A R_{-1}+\beta_{D 1,0} D_{1}+\beta_{D 2,0} D_{2}+\varepsilon$

The predictive capability of sentiment words is analysed by a regression (equation (10)), in which the adjusted return on the day after a disposal announcement $\left(A R_{+1}\right)$ is the dependent variable that is regressed on eight independent variables (two control variables, two dummy factors, and four main test variables). The control variables are again $\log M C$ and $\log P B$. Besides the detrended fractions of positive, negative, and uncertainty words, the fourth main variable tested is the announcement day adjusted return $\left(A R_{0}\right)$ to check whether it has a spillover effect.

$$
\begin{aligned}
& A R_{+1}=\alpha_{1}+\beta_{A R 0,1} A R_{0}+\beta_{\text {pos, } 1} \text { pos }+\beta_{\text {neg, } 1} \text { neg }+\beta_{\text {unc }, 1} u n c+\beta_{\log M C, 1} \log M C+ \\
& \beta_{\log P B, 1} \log P B+\beta_{D 1,1} D_{1}+\beta_{D 2,1} D_{2}+\varepsilon
\end{aligned}
$$

\footnotetext{
${ }^{15}$ All regressions conducted in this paper use ordinary least squares.
} 
Following the methodology adopted by Tetlock (2007), log trading volumes are detrended by 30 -day ${ }^{16}$ moving average trading volumes (equation (11)). A one-day lagged detrended trading volume $\left(D V L_{-1}\right)$ is used as a control variable, together with other control variables used in analysing the adjusted returns $-\log M C, \log P B, D_{1}$, and $D_{2}$ - to measure whether the sentiment words occurring in the RNS announcements or in the media stories can affect the detrended trading volumes on the announcement day (equation (12)). The one-day-after detrended trading volume $\left(D V L_{+1}\right)$ is regressed on the announcement day detrended trading volume $\left(D V L_{0}\right)$ and the detrended fractions of sentiment words to figure out whether their effects spill-over to the day after the original announcements (equation (13)).

$$
\begin{aligned}
& D V L_{t}=\log \left(\text { Volume }_{t}\right)-\text { Moving Average Log Volume } 30, t \\
& D V L_{0}=\alpha_{0}+\beta_{\text {pos }, 0} \text { pos }+\beta_{\text {neg, } 0} \text { neg }+\beta_{u n c, 0} u n c+\beta_{\log M C, 0} \log M C+\beta_{\log P B, 0} \log P B+ \\
& \beta_{D V L-1,0} D V L_{-1}+\beta_{D 1,0} D_{1}+\beta_{D 2,0} D_{2}+\varepsilon \\
& D V L_{+1}=\alpha_{1}+\beta_{D V L 0,1} D V L_{0}++\beta_{\text {pos }, 1} \text { pos }+\beta_{\text {neg, }, 1} \text { neg }+\beta_{\text {unc }, 1} u n c+\beta_{\log M C, 1} \log M C+ \\
& \beta_{\log P B, 1} \log P B+\beta_{D 1,1} D_{1}+\beta_{D 2,1} D_{2}+\varepsilon
\end{aligned}
$$

\section{Analysis of Results}

\subsection{Stylised Facts Concerning RNS Announcements and Media Stories}

Throughout a calendar year (Figure 1), compared with other months, there are slightly fewer disposal announcements in January, February, and October. Relatively more disposal decisions are disclosed in June, September, and December. However, overall, FTSE 100 companies' disposal announcements do not generally cluster at certain time points as earnings-related announcements do. They are generally spread across a calendar year. On the other hand, it seems that listed companies do choose to release their disposal decisions on a specific trading day (Figure 2): more than $40 \%$ of the sampled disposal announcements are made before the LSE opens (8:00 a.m.) while only 4\% of them are disclosed after the LSE has closed (16:30 p.m.). However, this time preference is irrelevant for the use of sentiment words in companies' announcements.

\footnotetext{
${ }^{16}$ In unreported results, if the raw trading volumes are detrended by a 60-day moving average, the conclusions about how sentiment words and control variables affect detrended trading volumes do not change.
} 
The descriptive statistics of RNS announcements are reported in panel A of Table 1. The length of announcements has a mean of 212 words but ranges from 30 to 1319 words. The means of the raw fractions of positive, negative, and uncertain words that occur in announcements are $0.93 \%, 0.45 \%$, and $0.61 \%$ respectively. Evidently, the raw fractions of sentiment words in disposal announcements are small. One of the reasons is that sentiment words do not occur in every announcement. In detail, $31.12 \%$ of these announcements do not include any positive words, and no negative (uncertainty) words occur in $45.92 \%$ $(33.16 \%)$ of the sampled announcements. If only the announcements which include at least one positive, negative, or uncertainty word are counted, the means of the raw fractions of positive, negative, and uncertainty words are $1.36 \%, 0.84 \%$, and $0.91 \%$ respectively. ${ }^{17}$

Figure 1 RNS Disposal Announcements Histogram (Calendar Year)

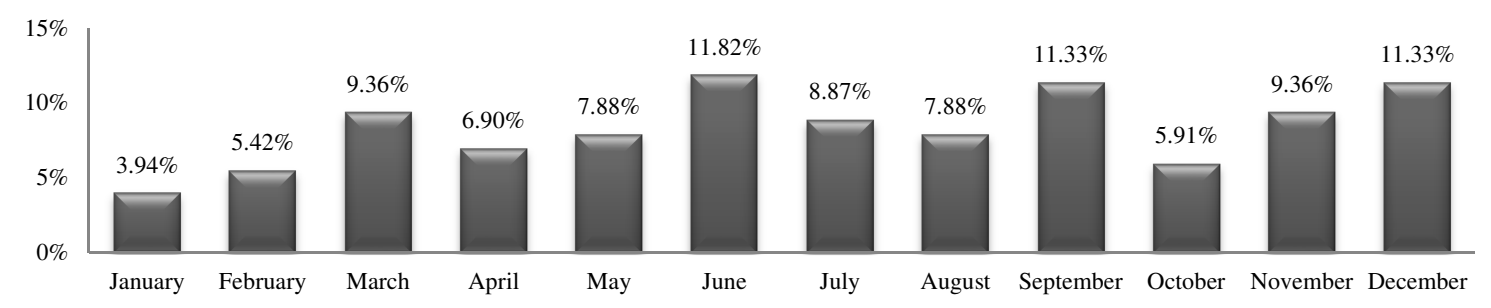

Figure 2 RNS Disposal Announcements Histogram (Trading Day)

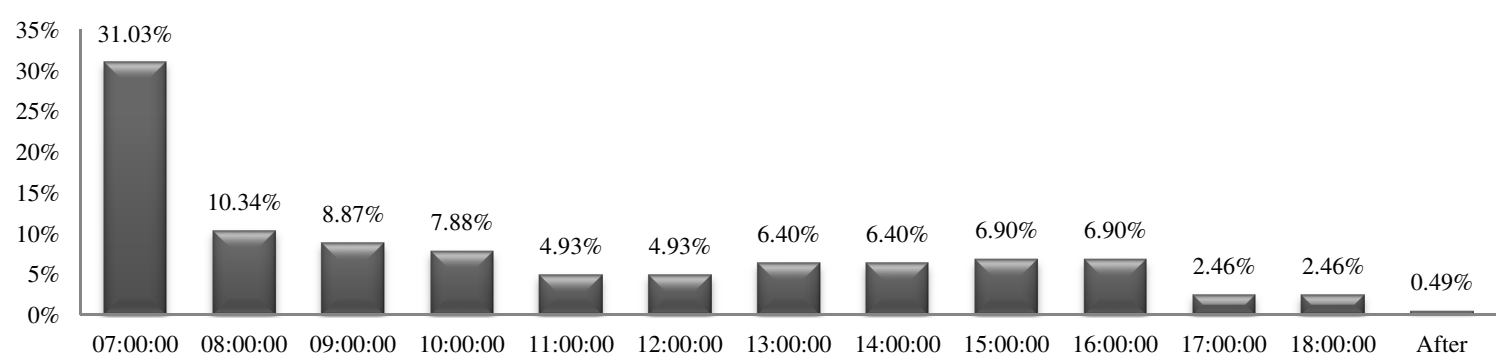

Panel B of Table 1 reports descriptive statistics of the corresponding media stories. Unlike those of RNS announcements, the average raw fractions of positive, negative, and uncertainty words used by the media are $0.59 \%, 1.06 \%$, and $0.38 \%$, respectively. Media journalists tend to use more negative words ( $\mathrm{t}$-statistic $=7.056$, $\mathrm{p}$-value $<0.001)$, fewer

\footnotetext{
${ }^{17}$ Loughran and McDonald (2011) report that, in the sample of $10-\mathrm{K}$ files, the mean fractions of positive, negative, and uncertainty words are $0.75 \%, 1.39 \%$, and $1.20 \%$, respectively. These fractions are also small but it seems that US companies use more negative and uncertainty words, while they use fewer positive words than their UK peers in disposal announcements.
} 
positive words (t-statistic $=-3.254, \mathrm{p}$-value $=0.001)$, and fewer uncertainty words $(\mathrm{t}$ statistic $=-3.566$, p-value $<0.001$ ). As reported in Table 2, the raw fraction of positive words in media stories is only affected by the occurrence of positive words in the original announcement $(\mathrm{t}$-statistic $=2.875, \mathrm{p}$-value $=0.005)$. Similarly, the raw fraction of negative words used by journalists is only influenced by the occurrence of negative words in the original announcement (t-statistic $=3.147$, p-value $=0.002$ ). However, the raw fraction of uncertainty words in the media stories cannot be explained by the occurrence of sentiment words in the original announcement (Table 2).Obviously, journalists are masters of words and are well versed in grabbing the public's attention. The mass media has a reputation for focusing on fear to sell stories. On the other hand, although abnormally optimistic language in earning announcements may increase the litigation risk faced by managers (Rogers et al., 2011), there is no evidence to show this relationship concerning other types of information disclosure. Therefore, it is not surprising to observe that more negative words and fewer positive words are used by journalists than by listed companies. In addition, managers have to leave some space for explanation and to reply to any censure from and legal liabilities of shareholders and regulators, while journalists face much less pressure as they are simply presenting their personal attitudes towards actual events. This may help to understand the finding that the original announcements include more uncertainty words than their corresponding media stories.

Table 1 Descriptive Statistics - RNS Announcements and Media Stories

\begin{tabular}{ccccccccc}
\hline Panel A & RNS Words & RNS Sentence & RNS POS & RNS NEG & RNS UNC & RNS pos & RNS neg & RNS unc \\
\hline Mean & 211.806 & 9.520 & $0.9345 \%$ & $0.4498 \%$ & $0.6102 \%$ & 1.0051 & 0.9461 & 0.9129 \\
Median & 141 & 7 & $0.9045 \%$ & $0.2623 \%$ & $0.4938 \%$ & 0.9627 & 0.5285 & 0.7614 \\
Stdev. & 190.115 & 7.588 & 0.0085 & 0.0058 & 0.0063 & 0.9181 & 1.2259 & 1.0052 \\
\hline Panel B & MASS Words & MASS Sentence & MASS POS & MASS NEG & MASS UNC & MASS pos & MASS neg & MASS unc \\
\hline Mean & 302.530 & 12.496 & $0.5939 \%$ & $1.0572 \%$ & $0.3797 \%$ & 0.9970 & 1.0013 & 1.0038 \\
Median & 296 & 12 & $0.5178 \%$ & $0.8439 \%$ & $0.2315 \%$ & 0.9878 & 0.8540 & 0.6711 \\
Stdev. & 171.952 & 6.740 & 0.0068 & 0.0086 & 0.0043 & 1.0654 & 0.8050 & 1.1432 \\
\hline
\end{tabular}

Table 2 Regression Results - Whether Media Stories Are Affected by Announcements

\begin{tabular}{l|c|ccc}
\hline & & \multicolumn{3}{|c}{ Dependent Variables } \\
\hline & N=141 & Mass POS & Mass NEG & Mass UNC \\
\hline \multirow{5}{*}{ Independent Variables } & \multirow{2}{*}{ RNS POS } & $\mathbf{0 . 2 2 7 4 * * *}$ & 0.0997 & 0.0080 \\
& & $\mathbf{( 2 . 8 7 4 6 )}$ & $(1.0024)$ & $(0.1537)$ \\
\cline { 2 - 5 } & \multirow{2}{*}{ RNS NEG } & -0.0063 & $\mathbf{0 . 5 2 5 7 * * *}$ & -0.0440 \\
\cline { 2 - 5 } & & $(-0.0475)$ & $\mathbf{( 3 . 1 4 7 5 )}$ & $(-0.5007)$ \\
\cline { 2 - 5 } & \multirow{2}{*}{ RNS UNC } & 0.0035 & -0.1757 & 0.0414 \\
& & $(0.0296)$ & $(-1.1869)$ & $(0.5312)$ \\
\cline { 2 - 5 }
\end{tabular}




\begin{tabular}{c|c|ccc}
\cline { 2 - 4 } & Intercept & $\begin{array}{c}\mathbf{0 . 0 0 3 9} \\
\mathbf{( 2 . 6 9 3 1 )}\end{array}$ & $\begin{array}{c}\mathbf{0 . 0 0 8 6 * * *} \\
\mathbf{( 4 . 7 4 2 4})\end{array}$ & $\begin{array}{c}\mathbf{0 . 0 0 3 7} \\
\mathbf{( 3 . 8 4 5 * *}\end{array}$ \\
\hline & Adjusted $\mathrm{R}^{2}$ & 0.0494 & 0.0699 & -0.0216 \\
\hline
\end{tabular}

The reported results are adjusted by White test if there is heteroscedasticity in residuals.

Numbers in brackets are $\mathrm{t}$-statistics

*** refers to significant at $1 \%$ critical level;

** refers to significant at $5 \%$ critical level

$*$ refers to significant at $10 \%$ critical level

In total, LMFSD defines 353 positive words, 2337 negative words, and 285 uncertainty words. The distribution of sentiment words used by disposal disclosures in the UK is similar to Loughran and McDonald's (2011) findings from the 10-K files in the US that, "there are typically a small number of very high-frequency words and a large number of low-frequency words". Table 3 reports the top 10 high-frequency sentiment words in RNS disposal announcements (panel A) and in media stories (panel B). The top ten highfrequency words account for the majority of sentiment words occurring in the sampled disposal announcements. In the sampled media stories, although the top ten positive and uncertainty words also account for more than $50 \%$ of the occurrence of these two types of sentiment words, journalists exhibit a much richer negative words pool. In total, 140 unique negative words occur at least once in the sampled media stories while there are only 41 unique negative words in the original announcements. As a consequence, the top ten highfrequency negative words only account for $35 \%$ of the total occurrence of negative words in the corresponding media stories compared with $79 \%$ in the original disposal announcement.

Table 3High-Frequency Sentiment Words in RNS Announcements and in Media Stories

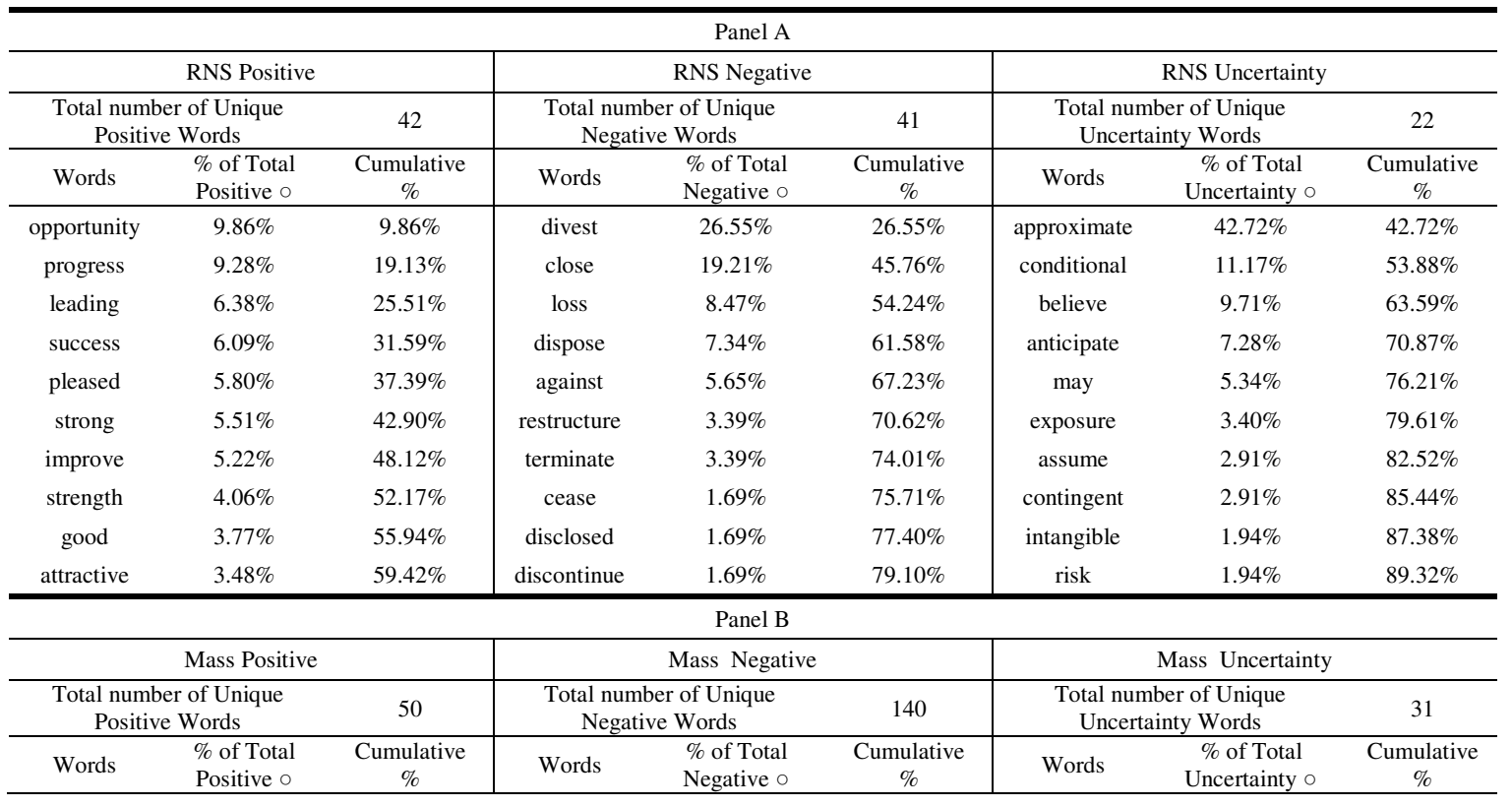




\begin{tabular}{ccc|ccc|ccc}
\hline strong & $10.75 \%$ & $10.75 \%$ & divest & $6.31 \%$ & $6.31 \%$ & may & $15.00 \%$ & $15.00 \%$ \\
improve & $7.94 \%$ & $18.69 \%$ & close & $4.37 \%$ & $10.68 \%$ & could & $14.38 \%$ & $29.38 \%$ \\
profitability & $7.48 \%$ & $26.17 \%$ & dispose & $4.13 \%$ & $14.81 \%$ & believe & $11.25 \%$ & $40.63 \%$ \\
opportunity & $5.61 \%$ & $31.78 \%$ & loss & $4.13 \%$ & $18.93 \%$ & almost & $6.25 \%$ & $46.88 \%$ \\
good & $4.67 \%$ & $36.45 \%$ & cut & $3.88 \%$ & $22.82 \%$ & possible & $5.00 \%$ & $51.88 \%$ \\
leading & $4.67 \%$ & $41.12 \%$ & disaster & $3.16 \%$ & $25.97 \%$ & exposure & $5.00 \%$ & $56.88 \%$ \\
great & $4.21 \%$ & $45.33 \%$ & crisis & $2.67 \%$ & $28.64 \%$ & speculate & $4.38 \%$ & $61.25 \%$ \\
success & $4.21 \%$ & $49.53 \%$ & decline & $2.43 \%$ & $31.07 \%$ & risk & $4.38 \%$ & $65.63 \%$ \\
attractive & $3.27 \%$ & $52.80 \%$ & failed & $2.43 \%$ & $33.50 \%$ & suggest & $3.75 \%$ & $69.38 \%$ \\
gain & $3.27 \%$ & $56.07 \%$ & against & $1.94 \%$ & $35.44 \%$ & probable & $3.75 \%$ & $73.13 \%$ \\
\hline
\end{tabular}

$\circ \%$ of Total Positive $=$ Frequency of Positive Word $i /$ Total Occurrence of Positive Words

$\%$ of Total Negative $=$ Frequency of Negative Word $i$ / Total Occurrence of Negative Words

$\%$ of Total Uncertainty $=$ Frequency of Uncertainty Word $i /$ Total Occurrence of Uncertainty Words

\subsection{Information Sentiment and Adjusted Returns}

If the information delivered by listed companies and by journalists are both credible for shareholders, unexpected positive (negative) information, on average, should strengthen (weaken) stock prices. Therefore, the detrended fraction of positive (negative) words should positively (negatively) influence the announcement day adjusted return $\left(A R_{0}\right)$, which mainly reflects the average market reaction to firm specific information - the disposal decision. As modern financial theory typically presumes that shareholders are risk averse, the adjusted return on the announcement day may be negatively related to the unexpected uncertainty information because risk-averse shareholders require higher compensation for bearing the increase risk revealed by abnormal levels of uncertainty words. The detrended fraction of uncertainty words is thus expected to negatively affect the announcement day adjusted return.

Hypothesis 1: The detrended fraction of positive words has positive effects on $A R_{0}$. The detrended fraction of negative words has negative effects on $A R_{0}$. The detrended fraction of uncertainty words has negative effects on $A R_{0}$.

When all announcements are analysed in an integrated sample, only the detrended fraction of negative words in the announcement significantly affects the announcement day adjusted return (column "Whole" in panel A of Table 4). The abnormal level of negative information in the announcement leads to a lower adjusted return on the announcement day. None of the control variables is significant in this context. However, the sub-sample results suggest that the significant effects caused by the detrended negative words are mainly due to those announcements which do not have any corresponding media story. When announcements without corresponding media stories are analysed separately, the announcement day adjusted return negatively correlates with the detrended fraction of 
negative words, but neither the effects of the positive words nor the uncertainty words are statistically significant (column "RNS Only" in panel A of Table 4). Conversely, if the original announcements are followed by journalists' stories (column "Cor. RNS" in panel A of Table 4), the detrended fraction of negative words in the announcement loses its ability to explain the announcement day adjusted returns; and the detrended fractions of positive and uncertainty words are not explanatory either in this context (column "Cor. RNS" in panel A of Table 4).

\section{Table 4 Information Sentiment and Announcement Day Adjusted Returns $\left(A R_{0}\right)$}

"Whole" means that all RNS disposal announcements are pooled and analysed as an integrated sample. "Cor. RNS" is a sub-sample that only includes the announcements which have at least one corresponding media story. The disposal decisions in the Cor. RNS sub-sample are tested by two regressions to analyse the effects of the sentiment information in the original RNS disposal announcements and in the mass media stories on the stock price changes. "RNS Only" is the sub-sample which includes only the disposal announcements that do not have any corresponding media stories. Therefore, this sub-sample is tested to convey the potential effects related to the sentiment information in the original announcements, regardless of any possible interaction between the tone of listed companies' and journalists' stories.

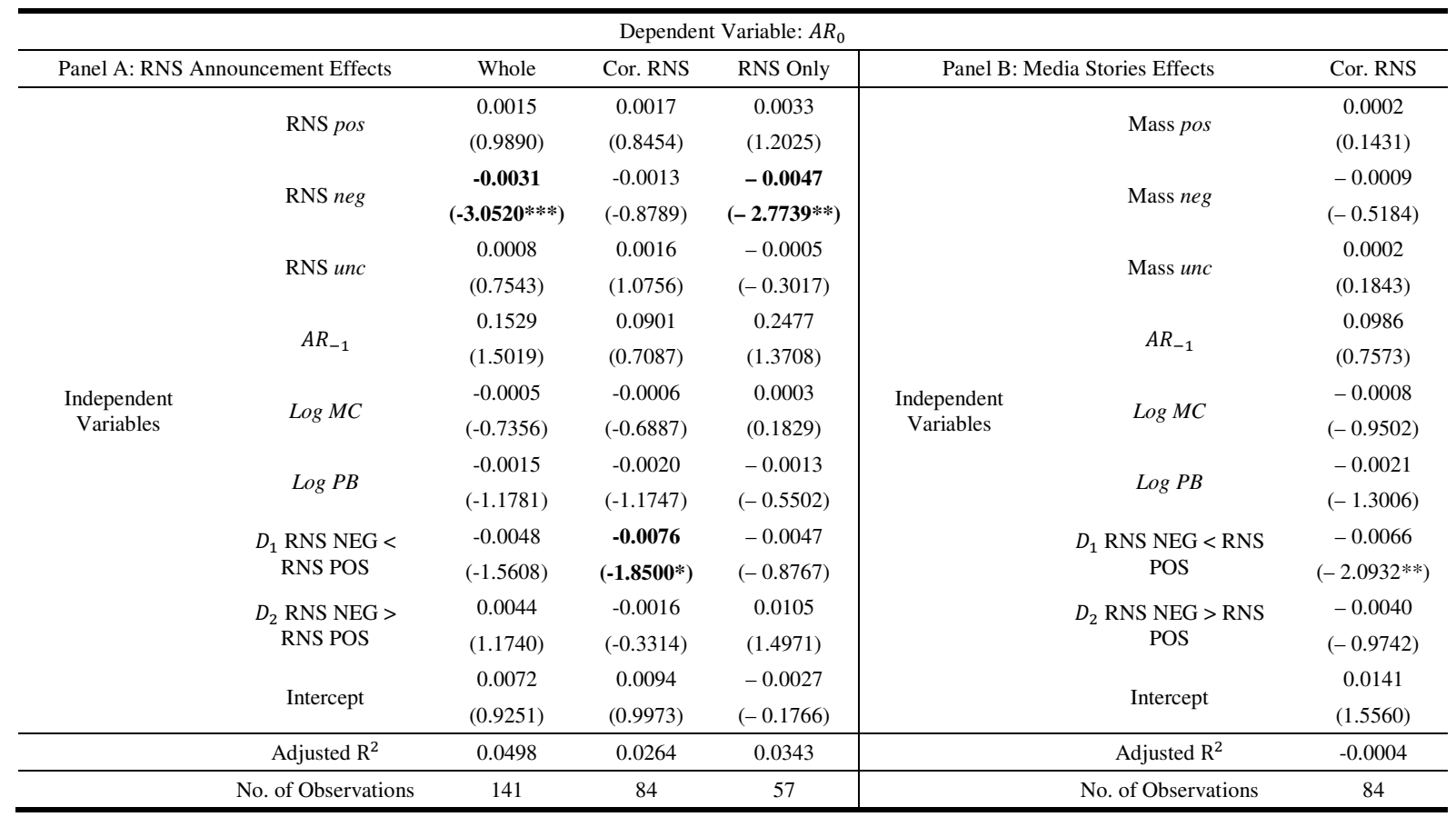

None of the three types of sentiment information that are expressed in journalists' stories is able to explain the share price changes on the announcement day (panel B of Table 4). The lower explanatory power of media sentiment for the announcement day adjusted return might be because of the time lag between the media stories and the original announcement. In the sub-sample Cor. RNS, $38.9 \%$ of the media stories were published at least one day after the original announcement. In this sub-sample, the optimism dummy variable $D_{1}$ is significant at the $90 \%$ confidence level, which shows that investors' average 
reaction towards the disposal disclosure is marginally negative when the original announcement has more positive words than negative ones or, alternatively, the original announcement discloses a generally optimistic tone.

Although the negative words in the news stories of DJNS and WSJ statistically predict the stock market returns on the day after the news is published (Tetlock et al., 2008), this paper emphasises the informational efficiency of the UK stock market. If the UK stock market is efficient, sentiment information in the disposal announcement should be fully reflected by price changes as soon as the announcement is publicly available via RNS and, therefore, is less likely to affect price movements on the day following the announcement when there is no other new information. Similarly, the historic price performance $\left(A R_{0}\right)$ should not be able to predict future price changes $\left(A R_{+1}\right)$.

Hypothesis 2: The detrended fractions of positive, negative, and uncertainty words do not have a predictive capability for $A R_{+1}$. The adjusted return on the announcement day $\left(A R_{0}\right)$ is not informative to forecast $A R_{+1}$.

The statistical results (Table 5) suggest that the UK stock market might not be as informationally efficient as it is presumed to be in Hypothesis 2. Although the whole sample results indicate that neither the detrended fraction of sentiment words nor the adjusted return on the announcement day significantly affect the adjusted return on the day following the original announcement (the "Whole" column in panel A of Table 5), historic information can be informative in the two sub-samples.

Table 5 Information Sentiment and Future Adjusted Returns $\left(A R_{+1}\right)$

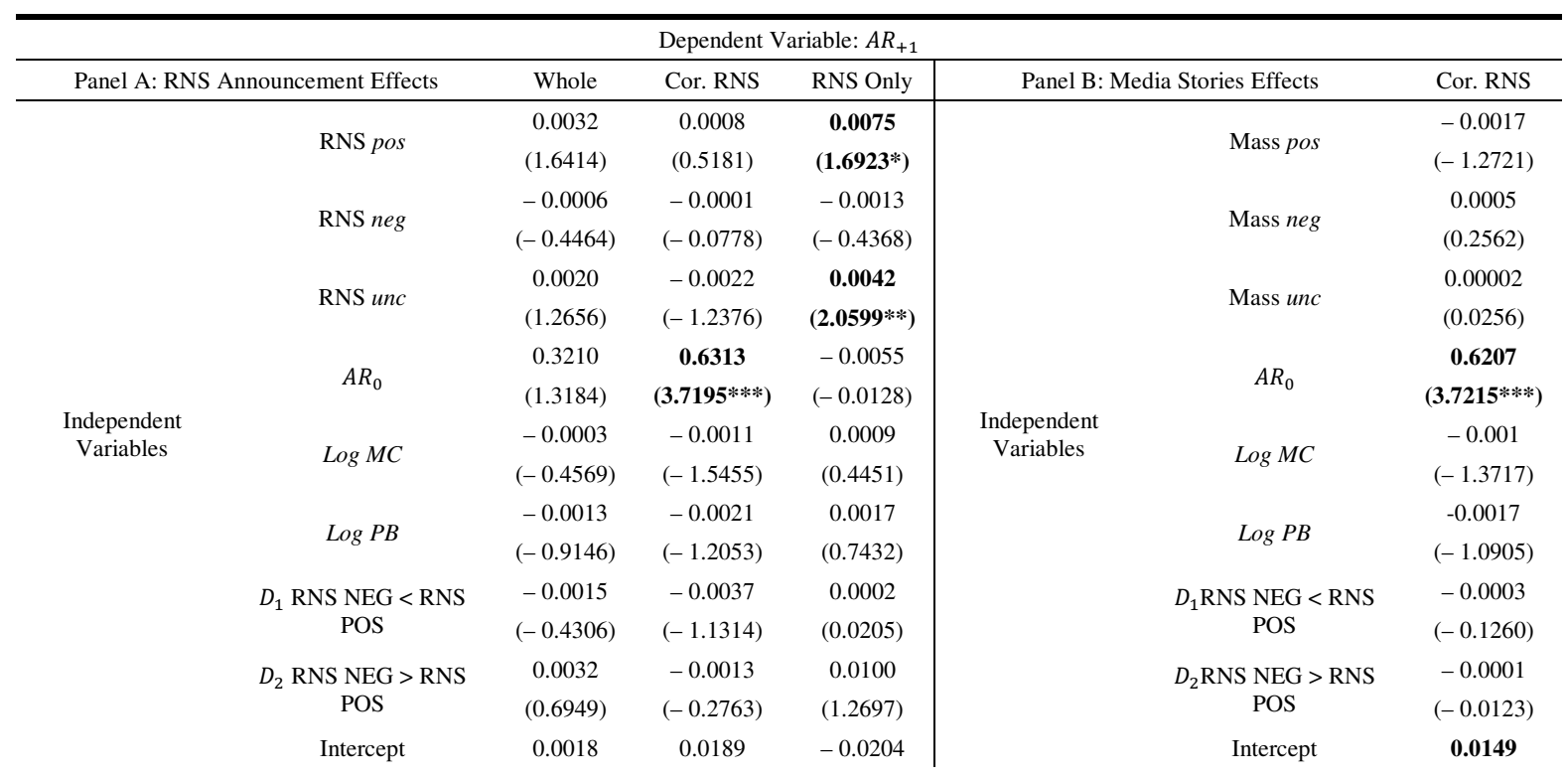




\begin{tabular}{cccc|cr} 
& $(0.2149)$ & $(2.1034 * *)$ & $(-0.9724)$ & $(\mathbf{1 . 9 4 8 7 * )}$ \\
\hline Adjusted $\mathrm{R}^{2}$ & 0.0557 & 0.3027 & 0.0073 & ${\text { Adjusted } \mathrm{R}^{2}}^{0.2956}$ \\
\hline No. of Observations & 141 & 84 & 57 & No. of Observations & 84 \\
\hline
\end{tabular}

If there are no corresponding media stories, the detrended fractions of positive and uncertainty words positively affect the adjusted return on the next trading day but the announcement day adjusted return is not informative in this context (the "RNS Only" column in panel A of Table 5). On the other hand, if the original disposal announcement is followed by journalists' stories, all three types of sentiment information, released either by the announcement ("Cor. RNS" column in panel A of Table 5) or by the media stories (panel B of Table 5), do not significantly affect the future adjusted returns, but the positive impact of the announcement day adjusted return becomes significant.

Media coverage is a relatively stable characteristic of listed companies so that firms enjoying high levels of media coverage are likely to continue to have high media coverage in the future; for those firms with lower media exposure, the converse will be true(Fang and Peress, 2009). Investors, especially sophisticated ones, can observe and judge this characteristic according to their past experience of the stock market. Therefore, when a company which is used to catching the mass media's attention announces a strategy of writing down a section of its assets, market participants might tend to postpone their conclusive judgements or reactions towards the announcement to wait for the media stories, which are considered to be more credible than corporate announcements (Kothari et al., 2009). This might explain why, in the Cor. RNS sub-sample, the detrended fraction of RNS negative words cannot explain the announcement day adjusted returns (Table 4) and historic price information can predict future adjusted returns (Table 5).

Market participants finally digest mass media stories at some point after the original regulatory announcement, usually after normal trading hours on the announcement day or from the following morning's newspapers, when the tone of the original announcement has been blended with that of the mass media. In this situation, it is difficult to analyse those effects caused by the announcement and those caused by the mass media stories separately. When a more optimistic listed company announcement is compared with a more pessimistic mass media story, market participants may have to react to both, which challenges their information-processing capabilities. Alternatively, price movements on the announcement day become a plain benchmark for shareholders' decision-making. In addition, consistent with major previous studies (Tetlock, 2007; Tetlock et al., 2008; 
Loughran and McDonald, 2011), although the effects of sentiment words are statistically significant, they are not economically significant. On the other hand, the impact of the announcement day's adjusted returns on the following day adjusted return is both statistically and economically significant.

\subsection{Information Sentiment and Detrended Trading Volumes}

Trading volumes react to breaking new market information as an increasing function of differential precision across shareholders (Kim and Verrecchia, 1991). In addition to the fact that textual expression of sentiment information may be interpreted very differently by investors (Brun and Teigen, 1988), the more sentiment information delivered by a story the larger the dispersion of shareholders' decisions will be. Extra positive, negative, or uncertainty words in the press might all show an inverse relationship with announcement day trading volumes.

Hypothesis 3: The detrended fractions of positive, negative and uncertainty words that are released by RNS disposal announcements and media stories are positively related to the announcement day detrended trading volume.

When all RNS disposal announcements have been analysed in an integrated sample, only the detrended fraction of negative words in companies' announcements seem to significantly affect the announcement day detrended trading volume (the "Whole" column in panel A of Table 6). Four of the five control variables are significant in this context. The previous day's detrended trading volumes positively affect the announcement day's detrended trading volume. Company size, price to book ratio, and the dummy factor, reflect that pessimistic announcements are inversely related to the announcement day detrended trading volume.

Table 6 Information Sentiment and Announcement Day Detrended Trading Volumes $\left(D V L_{0}\right)$

\begin{tabular}{|c|c|c|c|c|c|c|c|}
\hline \multicolumn{8}{|c|}{ Dependent Variable: $D V L_{0}$} \\
\hline \multicolumn{2}{|c|}{ Panel A: RNS Announcement Effects } & \multirow{2}{*}{$\begin{array}{c}\text { Whole } \\
-0.0273 \\
(-1.2407)\end{array}$} & \multirow{2}{*}{$\begin{array}{c}\text { Cor. RNS } \\
-0.0108 \\
(-0.3905)\end{array}$} & \multirow{2}{*}{$\begin{array}{c}\text { RNS Only } \\
-0.0484 \\
(-1.3145)\end{array}$} & \multicolumn{2}{|c|}{ Panel B: Media Stories Effects } & \multirow{2}{*}{$\begin{array}{c}\text { Cor. RNS } \\
0.0007 \\
(0.0347)\end{array}$} \\
\hline \multirow{5}{*}{$\begin{array}{l}\text { Independent } \\
\text { Variables }\end{array}$} & RNS pos & & & & \multirow{5}{*}{$\begin{array}{c}\text { Independent } \\
\text { Variables }\end{array}$} & Mass pos & \\
\hline & RNSneg & $\begin{array}{c}\mathbf{0 . 0 4 0 8} \\
(2.8323 * * *)\end{array}$ & $\begin{array}{c}0.0448 \\
(2.3204 * *)\end{array}$ & $\begin{array}{c}0.0276 \\
(1.1242)\end{array}$ & & Mass neg & $\begin{array}{c}0.0320 \\
(1.3349)\end{array}$ \\
\hline & RNSunc & $\begin{array}{l}-0.0144 \\
(-0.9917)\end{array}$ & $\begin{array}{c}-0.0073 \\
(-0.3648)\end{array}$ & $\begin{array}{c}-0.0310 \\
(-1.0156)\end{array}$ & & Mass unc & $\begin{array}{c}0.0104 \\
(0.6956)\end{array}$ \\
\hline & $D V L_{-1}$ & $\begin{array}{c}0.4380 \\
(5.2900 * * *)\end{array}$ & $\begin{array}{c}0.3633 \\
(3.5608 * * *)\end{array}$ & $\begin{array}{c}0.4640 \\
(2.9856 * * *)\end{array}$ & & $D V L_{-1}$ & $\begin{array}{c}0.3477 \\
(3.3511 * * *)\end{array}$ \\
\hline & $\log M C$ & $\begin{array}{c}-0.0270 \\
\left(-2.6635^{* * *}\right)\end{array}$ & $\begin{array}{c}-0.0322 \\
(-2.8092 * * *)\end{array}$ & $\begin{array}{l}-0.0089 \\
(-0.4451)\end{array}$ & & $\log M C$ & $\begin{array}{c}-0.0310 \\
(-2.7111 * * *)\end{array}$ \\
\hline
\end{tabular}




\begin{tabular}{|c|c|c|c|c|c|}
\hline $\log P B$ & $\begin{array}{c}-0.0404 \\
(-2.1792 * *)\end{array}$ & $\begin{array}{l}-0.0209 \\
(-0.9103)\end{array}$ & $\begin{array}{c}-0.0690 \\
(-2.4897 * *)\end{array}$ & $\log P B$ & $\begin{array}{l}-0.0122 \\
(-0.5465)\end{array}$ \\
\hline $\begin{array}{c}D_{1} \text { RNS NEG }<\text { RNS } \\
\text { POS }\end{array}$ & $\begin{array}{l}-0.0606 \\
(-1.3924)\end{array}$ & $\begin{array}{c}-0.0781 \\
(-1.4247)\end{array}$ & $\begin{array}{c}-0.0451 \\
(-0.4775)\end{array}$ & $\begin{array}{c}D_{1} \text { RNS NEG < } \\
\text { RNS POS }\end{array}$ & $\begin{array}{c}-0.0885 \\
(-2.1325 * *)\end{array}$ \\
\hline $\begin{array}{c}D_{2} \text { RNS NEG }>\text { RNS } \\
\text { POS }\end{array}$ & $\begin{array}{c}-0.1662 \\
(-3.1779 * * *)\end{array}$ & $\begin{array}{c}-0.1973 \\
(-3.1293 * * *)\end{array}$ & $\begin{array}{c}-0.0874 \\
(-0.8610)\end{array}$ & $\begin{array}{c}D_{2} \text { RNS NEG > } \\
\text { RNS POS }\end{array}$ & $\begin{array}{c}-0.1255 \\
(-2.2707 * *)\end{array}$ \\
\hline Intercept & $\begin{array}{c}0.3675 \\
\left(3.3516^{* * *}\right)\end{array}$ & $\begin{array}{c}0.4029 \\
(3.1584 * * *)\end{array}$ & $\begin{array}{c}0.2318 \\
(1.2052)\end{array}$ & Intercept & $\begin{array}{c}0.3600 \\
(2.9489 * * *)\end{array}$ \\
\hline Adjusted $\mathrm{R}^{2}$ & 0.2415 & 0.2342 & 0.2023 & Adjusted $\mathrm{R}^{2}$ & 0.2077 \\
\hline No. of Observations & 141 & 84 & 57 & No. of Observations & 84 \\
\hline
\end{tabular}

When analysing the two sub-samples separately, although the one-day lagged detrended trading volume positively relates to the announcement day detrended trading volume in both samples, the sentiment variables and other control variables affect it differently. When the original announcement is accompanied by media stories (the "Cor. RNS" column in panel A of Table 6), the abnormal extent of more negative words leads to a higher detrended trading volume on the announcement day; company size negatively affects the detrended trading volume but the impacts on the price-to-book (P/B) ratio are limited; and if there are more negative words than positive ones in the original announcement (pessimism), the detrended trading volume also tends to be lower. On the other hand, in a situation where the original announcement is not tracked by journalists (the "RNS Only" column in panel A of Table 6), the P/B ratio negatively affects the announcement day detrended trading volume but market capitalisation does not; and the pessimism dummy variable is not significant in this sub-sample. In addition, as with the conclusion drawn from the announcement day adjusted return analysis, the sentiment information in the corresponding media stories does not influence the announcement day detrended trading volume (panel B of Table 6).

Table 7 Information Sentiment and Future Detrended Trading Volume $\left(D V L_{+1}\right)$

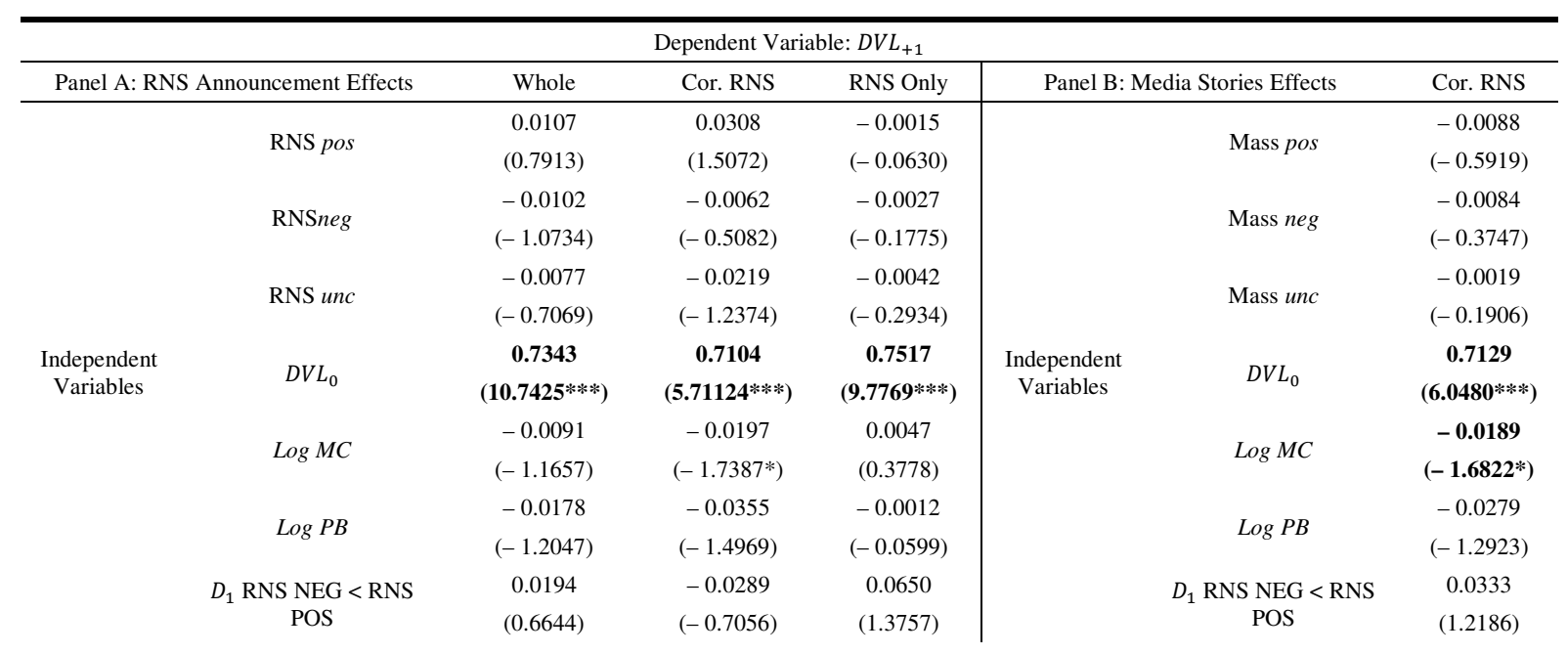




\begin{tabular}{|c|c|c|c|c|c|}
\hline $\begin{array}{c}D_{2} \text { RNS NEG }>\text { RNS } \\
\text { POS }\end{array}$ & $\begin{array}{c}0.0998 \\
(2.2970 * *)\end{array}$ & $\begin{array}{c}0.0903 \\
(1.4880)\end{array}$ & $\begin{array}{c}0.0838 \\
(1.3869)\end{array}$ & $\begin{array}{c}D_{2} \text { RNS NEG }>\text { RNS } \\
\text { POS }\end{array}$ & $\begin{array}{c}0.0975 \\
(1.5718)\end{array}$ \\
\hline Intercept & $\begin{array}{c}0.0784 \\
(0.9077)\end{array}$ & $\begin{array}{c}0.2175 \\
\left(1.6795^{*}\right)\end{array}$ & $\begin{array}{c}-0.0898 \\
(-0.6779)\end{array}$ & Intercept & $\begin{array}{c}0.1934 \\
(1.7039 *)\end{array}$ \\
\hline Adjusted $\mathrm{R}^{2}$ & 0.5610 & 0.4590 & 0.6619 & Adjusted $\mathrm{R}^{2}$ & 0.4387 \\
\hline No. of Observations & 141 & 84 & 57 & No. of Observations & 84 \\
\hline
\end{tabular}

Consistent with the findings regarding adjusted returns, the effects of negative words in announcements on the detrended trading volume are statistically significant, but are much less economically significant than those of the one-day lagged detrended trading volume. Combined with the findings of the announcement day adjusted return, in general, negative words in the original announcements have a more significant impact on market reactions. However, the occurrence of negative words affects shareholders' general expectations (adjusted returns) if the announcements are not accompanied by media news and does influence the range of their reactions (detrended trading volume) if the announcements are ignored by journalists.

As sentiment information has a similar impact on the announcement day adjusted return and detrended trading volume, the potential influence of sentiment information on the detrended trading volume on the following day is tested by a similar hypothesis that its impacts on trading volumes are restricted to the announcement day. Because the one-day lagged detrended trading volume is a statistically and economically significant explanatory variable, the detrended trading volume on the day after an announcement may exhibit the same trend.

Hypothesis 4: The detrended fractions of positive, negative, and uncertainty words occurring in the RNS disposal announcements or in the corresponding media stories do not affect the detrended trading volume on the day after the initial announcement. The announcement day detrended trading volume positively relates to the one-day after detrended trading volume.

The statistical results (Table 7) confirm that sentiment information disclosed by companies' announcements does not drive trading volumes the day after the announcement, regardless of the existence of corresponding media stories; and neither does the sentiment information delivered by the corresponding media stories. On the other hand, the detrended trading volume on the announcement day extends its influence to the day after and the positive coefficients are highly significant in all three samples. 
Combined with the results concerning future adjusted returns, the impact of sentiment information on shareholders' reactions only occurs on the day when an announcement is made. On the following trading day, shareholders are more likely to be affected by market performance on the announcement day, rather than by the information itself. This general result is not consistent with some previous studies (Tetlock, 2007; Tetlock et al., 2008; Loughran and McDonald, 2011) which convey the predictability of sentiment information, either from listed companies or from the media. This inconsistency might be explained from two perspectives. First, this paper analyses disposal announcements and their corresponding media stories while the analysis in previous studies has included all types of media news (Tetlock, 2007; Tetlock et al., 2008) or has focused on earnings related announcements (Loughran and McDonald, 2011). Second, information-driven market performance is tested in a five-day time window in this paper, so that all other regulatory information disclosures are excluded, while previous studies used a much longer time window - for example, 30days or even a whole year, where unrelated announcements may have confounded the inferences.

\section{Conclusions}

As long as a piece of information indicates a significant change in a company's fundamental values, it should drive shareholders' decisions and the company's share price performance. Previous empirical studies have found that information sentiment does play an important role in explaining share price and accounting performance during the period when the information is being disclosed. This paper extends these information-content studies from earnings-related information to disposal decisions so that the sentiment of listed companies' announcements and those of media journalists' stories could be compared. This paper addresses three core issues. First, listed companies and journalists do not project the same tone in their text about the same disposal strategy. Journalists are more pessimistic than listed companies and they have a richer negative word pool. Integrating with previous studies which demonstrate that analyst reports involve less sentiment information (Kohari et al., 2009) and media (analysts) cater to individual (institutional) investors (Fang and Peress, 2009), individual investors' irrational behaviour in financial markets might be a consequence of the information that they analyse presenting more sentiment information, which might be interpreted in varying ways in different situations (Brun and Teigen, 1988), 
than that controlled by financial institutions. Second, shareholders' reactions are driven by the sentiment information in listed companies' announcements rather than by that in media stories. Consistent with most previous studies in this area, the negative words that occur in disposal announcements play a much more crucial role than positive and uncertainty words in explaining information-related market performance. Although the effects on adjusted returns and detrended trading volumes caused by negative words are statistically significant, they are not economically significant; and their effects are mainly restricted to the day when the disposal announcement is disclosed. The better model fit indicates that the abnormal number of negative words in announcements have more explanatory power for the dispersion of expectations among investors (trading volumes) than for their average reaction (returns). Last but not least, media coverage affects how shareholders respond to a disposal announcement. The occurrence of negative words in a disposal announcement is an explanatory variable for shareholders' overall reaction (adjusted returns) only in the context that the original announcement has not been reported by the mass media. On the other hand, only when the original announcement is accompanied by journalists' enthusiasm are the abnormally more negative words used in the announcements able to affect the range of decisions among investors (detrended trading volume).

In general, developed markets have higher media coverage, a better news transmission mechanism, and more advanced regulation schemes, so investors' reactions to information disclosures in mature stock markets are therefore significantly different from those in emerging markets (Griffin et al., 2011). As this study focuses on announcements and media news stories in a mature stock market (the UK), these conclusions might be more useful to participants in developed markets than to those in emerging markets. A question is left unsolved by analysing the sample used in this paper that may present a useful area for further research. Qualitatively, disposal announcements seem to weaken the explanatory ability of the detrended trading volume relating to the pre-announcement day on the announcement day detrended trading volume, but they strengthen the explanatory ability of the announcement day detrended trading volume the day after. However, this qualitative phenomenon cannot be quantitatively measured using the sample examined in this paper. 


\section{References}

Abrahamson, E. and Amir, E. (1996).The information content of the president's letter to shareholders. Journal of Business, Finance, and Accounting, Vol. 23, Issue 8, pp. 1157 $-1182$.

Antwiler, W. and Frank, M. Z. (2004). Is all that talk just noise? The information content of internet stock message boards. Journal of Finance, Vol. 59, Issue 3, pp. 1259 $-1294$.

Bamber, L. S. and Cheon, Y. S. (1995).Differential price and volume reactions to accounting earnings announcements. Accounting Review, Vol. 70, Issue 3, pp. 417 441.

Bagnoli, M., Beneis, M. D., and Was, S. G. (1999). Whisper forecasts of quarterly earnings per share. Journal of Accounting and Economics, Vol. 28, Issue 1, pp. 27 - 50.

Beaver, W. H. (1968). The information content of annual earnings announcements. Journal of Accounting Research, Vol. 6, pp. 67 - 92.

Berry, T. D. and Howe, K. M. (1994).Public information arrival. Journal of Finance, Vol. 49, Issue 4, pp. 1331 - 1346.

Botosan, C. A. (1997). Disclosure level and the cost of equity capital. Accounting Review, Vol. 72, Issue 3, pp. 323 - 349.

Brun, W. and Teigen, K. H. (1988). Verbal probabilities: ambiguous, contextdependent, or both? Organisational Behavior and Human Decision Processes, Vol. 41, Issue 3, pp. $390-404$.

Bushee, B. J. and Miller, G. S. (2007).Investor relations, firm visibility, and investor following. Accounting Review, Vol. 87, Issue 3, pp. 867 - 897.

Carreta, A., Farina, V., and Marelli, D. (2011). The impact of corporate governance press news on stock market returns. European Financial Management, Vol. 17, Issue 1, pp. $100-119$.

Cavalho, C., Klage, N., and Moench, E. (2011). The persistent effects of a false news shock. Journal of Empirical Finance, Vol. 18, Issue 4, pp. 597 - 615.

Clarkson, P. M., Joyce, D., and Tutticci, I. (2006).Market reaction to takeover rumour in Internet Discussion Site. Accounting and Finance, Vol. 46, Issue 1, pp. 31 - 52. 
Clatworthy, M. A. and Jones, J. (2006).Differential patterns of textual characteristics and company performance in the chairman's statement. Accounting, Auditing, and Accountability Journal, Vol. 19, Issue 4, pp. 493 - 511.

Collins, D. and Henning, S. (2004). Write-down timeliness, line-of-business disclosures and investors' interpretations of segment divestiture announcements. Journal of Business Finance and Accounting, Vol. 31, Issues 9 and 10, pp. 1261 - 1299.

Diether, K. B., Christopher, H. M., and Scherbina, A. (2002).Differences of opinion and the cross section of stock returns. Journal of Finance, Vol. 57, Issue 5, pp. $2113-2141$. Ederington, L. H. and Lee, J. H. (1993). How markets process information: news releases and volatility. Journal of Finance, Vol. 48, Issue 4, pp. 1161 - 1191.

Engelberg, J. E. and Parsons, C. A. (2011).The causal impact of media in financial markets. Journal of Finance, Vol. 66, Issue 1, pp. 67 - 97.

Fang, L. and Peress, J. (2009).Media coverage and the cross-section of stock returns. Journal of Finance, Vol. 64, Issue 5, pp. 2023 - 2052.

Griffin, J. M., Hirschey, N. H., and Kelly, P. J. (2011). How important is the financial media in global markets? Review of Financial Studies, Vol. 24, Issue 2, pp. 143 - 168.

Guillanmon-Saorin, E., Osma, B. G., and Jones, M. J. (2012).Opportunistic disclosure in press release headlines. Accounting and Business Research, Vol. 42, Issue 2, pp. 143 $-168$.

Gurun, U. G. and Butler, A. W. (2012). Don't believe the hype: local media slant, local advertising, and firm value. Journal of Finance, Vol. 67, Issue 2, pp. 561 - 579.

Henry, E. (2008). Are investors influenced by how earnings press realises are written? Journal of Business Communication, Vol. 45, Issue 4, pp. 363 - 407.

Hollander, S., Pronk, M., and Roelofsen, E. (2010). Does silence speak? An empirical analysis of disclosure choices during conference calls. Journal of Accounting Research, Vol. 48, Issue 3, pp. $531-563$.

Huberman, G. and Regev, T. (2001). Contagious speculation and a cure for cancer: a non-event that made stock prices soar. Journal of Finance, Vol. 56, Issue 1, pp. 387 396. 
Iselin, E. R. (1988). The effect of information load and information diversity on decision quality in a structured decision task. Accounting, Organization and Society, Vol. 13, No. 2, pp. $147-164$.

Kasznik, R. and Lev, B. (1995). To warn or not to warn: management disclosures in the face of an earnings surprise. Accounting Review, Vol. 70, Issue 1, pp. 113 - 134.

Kim, O. and Verrecchia, R. E. (1991).Trading volume and price reactions to public announcements. Journal of Accounting Research, Vol. 29, Issue 2, pp. 302 - 321.

Klibanoff, P. Lamon, O., and Wizman, T. A. (1998).Investor reaction to salient news in closed-end country funds. Journal of Finance, Vol. 53, Issue 2, pp. $673-699$.

Kothari, S. P., Li, X., and Short, J. E. (2009). The effect of disclosures by management, analysts, and business press on cost of capital, return volatility, and analyst forecasts: a study using content analysis. Accounting Review, Vol. 84, Issue 5, pp. 1639 - 1670.

Lee, C. M. C. and Swaminathan, B. (2000).Price momentum and trading volume.Journal of Finance, Vol. 55, Issue 5, pp. 2017 - 2069.

Loughran, T. and McDonald, B. (2011) When is a liability not a liability? Textual analysis, dictionaries, and 10-Ks. Journal of Finance, Vol. 66, Issue 1, pp. 35 - 65.

Mayhew, W. J. and Wenkatachalam, M. (2012). The power of voice: managerial affective states and future firm performance. Journal of Finance, Vol. 67, Issue 1, pp. 1 $-43$.

Mercer, M. (2004). How do investors assess the credibility of management disclosures? Accounting Horizons, Vol. 18, Issue 3, pp. 185 - 196.

Muiño, F. and Trombetta, M. (2009). Does graph disclosure bias reduce the cost of equity capital? Accounting and Business Research, Vol. 39, Issue 2, pp. 83 - 102.

Rogers, J. L., Buskirk, A. V., and Zechman, S. L. C. (2011).Disclosure tone and shareholder litigation. Accounting Review, Vol. 86, Issue 6, pp. 2155 - 2183.

Schleicher, T. and Walker, M. (2010). Bias in the tone of forward-looking narratives. Accounting and Business Research, Vol. 40, Issue 4, pp. 371 - 390.

Skinner, D. J. (1994). Why firms voluntarily disclose bad news. Journal of Accounting Research, Vol. 32, Issue 1, pp. 38 - 60. 
Solomon, D. H. (2012). Selective publicity and stock prices. Journal of Finance, Vol. 7 , Issue 2, pp. $599-637$.

Strong, J. S. and Meyer, J. R. (1987). Asset writedowns: managerial incentives and security returns. Journal of Finance, Vol. 42, Issue 3, pp. 643 - 661.

Tetlock, P. C. (2007). Giving content to investor sentiment: the role of media in stock market. Journal of Finance, Vol. 62, Issue 3, pp. 1139 - 1168.

Tetclok, P. C. (2011). All the news that's fit to reprint: do investors react to stale information? Review of Financial Studies, Vol. 24, Issue 5, pp. 1481 - 1512.

Tetlock, P. C., Saar-Tsechansky, M., and Macskassy, S. (2008). More than words: quantifying language to measure firms' fundamentals. Journal of Finance, Vol. 63, Issue 3, pp. $1437-1467$.

Visscherrs, V. H. M., Meerten, R. M., Passchier, W. W. F., and De Vries, N. N. K. (2009). Probability information in risk communication: a review of the research literature. Risk Analysis: An International Journal, Vol. 29, Issue 2, pp. 267-287.

Zhang, X. F. (2006). Information uncertainty and stock returns. Journal of Finance, Vol. 61, Issue 1, pp. $105-136$. 